\title{
Investigations of differences in iron oxidation state inside single neurons from substantia nigra of Parkinson's disease and control patients using the micro-XANES technique
}

\author{
Joanna Chwiej · Dariusz Adamek • Magdalena Szczerbowska-Boruchowska • \\ Anna Krygowska-Wajs · Slawomir Wojcik · Gerald Falkenberg • \\ Anna Manka · Marek Lankosz
}

Received: 7 June 2006/ Accepted: 26 September 2006/Published online: 21 November 2006

(C) SBIC 2006

\begin{abstract}
X-ray absorption near edge structure spectroscopy was applied in order to investigate differences in iron chemical state between the nerve cells of substantia nigra (SN) representing Parkinson's disease (PD) and those of control cases. Autopsy samples were cut using a cryotome, and were not fixed and not embedded in paraffin. The comparison of the absorption spectra near the iron K-edge measured in melanized neurons from SN of PD and control samples did not show significant differences in iron oxidation state. Measurements of inorganic reference materials containing iron in the second and third oxidation states indicate that most of the iron in all the nerve cell bodies examined was oxidized and occurred as trivalent ferric iron $\left(\mathrm{Fe}^{3+}\right)$.
\end{abstract}

Keywords Parkinson's disease - Iron oxidation state · $\mathrm{X}$-ray absorption near edge structure spectroscopy · Single cell

J. Chwiej $(\bowtie) \cdot$ M. Szczerbowska-Boruchowska

S. Wojcik - A. Manka - M. Lankosz

Department of Nuclear Methods,

Faculty of Physics and Applied Computer Science,

AGH-University of Science and Technology,

Al. Mickiewicza 30, 30-059 Cracow, Poland

e-mail: chwiej@novell.ftj.agh.edu.pl

D. Adamek · A. Krygowska-Wajs

Institute of Neurology,

Collegium Medicum,

Jagiellonian University,

ul. Botaniczna 3, 31-503 Cracow, Poland

G. Falkenberg

Hamburger Synchrotronstrahlungslabor

HASYLAB at DESY, Notkestrasse 85,

22603 Hamburg, Germany

\section{Introduction}

Parkinson's disease (PD) is a slowly progressive illness classified in the group of neurodegenerative disorders. The most characteristic feature of this disorder is the loss of neuromelanin (NM) rich neurons and the presence of Lewy bodies in the area of substantia nigra (SN) of the midbrain [1-5]. The causes of cellular loss are enigmatic in most individuals [1]. However, one of the leading hypotheses suggests that oxidative stress triggers a cascade of events resulting ultimately in the death of nerve cells [2-5].

Every cell has chemical reactions involving the oxidation and reduction of molecules. These reactions can lead to the production of free radicals. Free radicals react with key organic substrates such as lipids, proteins, and DNA. Oxidation of these biomolecules can damage them, disturbing normal functions, and may contribute to a variety of disease states $[3,5]$. Oxidative stress occurs when the generation of reactive oxygen species (free radicals, reactive anions containing oxygen atoms, molecules containing oxygen atoms that can produce free radicals or are chemically activated by them) in a system exceeds its ability to neutralize and eliminate them [3]. It is important in this context that transition metals like $\mathrm{Fe}, \mathrm{Cu}$, and $\mathrm{Mn}$ can promote the generation of free radicals in Fenton's reaction (Eq. 1):

$\mathrm{M}^{\mathrm{n}+}+\mathrm{H}_{2} \mathrm{O}_{2} \rightarrow \mathrm{M}^{(\mathrm{n}+1)+}+\mathrm{OH}^{\bullet}+\mathrm{OH}^{-}$

$\mathrm{Fe}$ is especially important and has been widely studied in the context of neurodegeneration in PD [2, 6-9]. The accumulation of Fe in the area of human $\mathrm{SN}$ was examined using many measurement techniques, e.g., absorption spectrophotometry, Mössbauer 
spectroscopy, X-ray fluorescence microscopy, or magnetic resonance imaging. Most of the investigations were done for autopsy samples. However, it is necessary to mention the in vivo studies carried out with the use of magnetic resonance imaging or ultrasonography [10-12]. The results of Antonini et al. [10] obtained using magnetic resonance imaging showed an increased $\mathrm{Fe}$ deposition in SN of patients with PD. Zecca et al. [11] and Berg et al. [12] observed an increased echogenicity of the SN in patients with PD. On the basis of animal studies and postmortem analyses of human brain tissue they revealed that this echofeature was associated with increased Fe level and reduced $\mathrm{NM}$ content in the area of SN.

The notion of a higher Fe level in PD SN was supported by many experiments done on postmortem samples of brain [7, 13-18]. Griffiths et al. [13] using absorption spectrophotometry observed an elevated level of $\mathrm{Fe}$ in the parkinsonian SN and the lateral portion of the globus pallidus. Sofic et al. [14] noticed significant differences both in the content of total $\mathrm{Fe}$ and ferric $\mathrm{Fe}$ in postmortem $\mathrm{SN}$ of PD patients. The 176 and $225 \%$ increases in the levels of total and trivalent $\mathrm{Fe}$, respectively, were found for parkinsonian $\mathrm{SN}$ in comparison with age-matched controls. In another paper, Sofic et al. [15] on the basis of histochemical and biochemical investigations demonstrated that the content of total $\mathrm{Fe}$ increases selectively in parkinsonian SN zona compacta but not in the zona reticulata and that the increase of $\mathrm{Fe}$ content is mainly due to ferric Fe. Such results are not in agreement with those obtained by Morawski et al. [16] with the use of the particle-induced X-ray emission technique. According to their paper from 2005, the content of Fe in patients who died with PD was higher both in SN pars compacta and SN pars reticulata. The major finding of Gotz et al. [7] was that the Fe level increased with the severity of neuropathological changes in PD and was mainly due to increased transport through the blood-brain barrier in late stages of PD. In contrast to the studies presented above, investigations of autopsy samples done with the use of Mössbauer spectroscopy did not show any differences in the total amount of $\mathrm{Fe}$ in SN between PD and control brains [17, 18].

As one can see, there are some disagreements in the results obtained using different measurement techniques. Even if we assume that the content of $\mathrm{Fe}$ in the area of SN (or part of it) is elevated, we cannot link it directly to PD. One can infer it from the fact that clinical features of PD do not seem to be frequently reported in hemochromatosis, a common chronic human genetic disorder whose hallmark is systemic $\mathrm{Fe}$ overload. In fact the first report of coincidence symptoms of PD in patients with hemochromatosis was the paper of Costello et al. [19] from 2004. Earlier Nielsen et al. [20] reported some symptoms of PD in patients with hemochromatosis. However, the occurrence of some "parkinsonism" symptoms (like rigidity, bradykinesia, tremor, gait disturbances) does not necessarily mean that there is a true PD. In hemochromatosis, some symptoms of parkinsonism may be due to the Fe overload observed in basal ganglia and may not be caused by "true" PD (with inherent $\alpha$-synuclein-related pathology in SN). Therefore, in spite of some reports indicating the possibility of a link between the C282Y mutation in the HFE gene (responsible for hemochromatosis) and PD, for example, the work of Dekker et al. [21], the elucidation of a role of $\mathrm{Fe}$ in pathogenesis of PD seems to be still not an easy goal to achieve.

As already mentioned, the degeneration in PD concerns the NM reach neurons from $\mathrm{SN}$. NM has a strong binding capacity, especially for $\mathrm{Fe}$ [22]. For normal subjects up to $20 \%$ of $\mathrm{SN} \mathrm{Fe}$ is bound to NM (in the ferric form) [23]. The function of NM within the pigmented neurons is not fully known; however, according to the existing evidence it can play some protective role against free-radical damage either by direct inactivation of free-radical species or via its ability to chelate transition metals [23]. Gerlach et al. [23] suggested that an increased Fe level in PD SN may saturate Fe-chelating sites on $\mathrm{NM}$ and cause a looser association between Fe and NM. As a result, redox-active $\mathrm{Fe}$ could be released and involved in a Fenton-like reaction leading to an increased production of oxidative radicals. The results of Faucheux et al. [24] showed that the redox activity of NM aggregates in a group of parkinsonian patients increased significantly (by 69\%) and was highest in patients with the most severe neuronal loss. Such an overloading of NM with redox-active elements may contribute to oxidative stress and intraneuronal damage in patients with PD [24]. On the other hand, it is necessary to mention that extraneuronal NM from dying neurons is phagocytosed by microglia and is associated with its activation. The release of neurotoxic microglial factors may lead to a subsequent aggravation of neurodegeneration [25].

An increased level of Fe in PD SN or single nerve cells of this area, however interesting, does not give the final answer whether Fe initiates or promotes neuronal degeneration or whether it accumulates as a consequence of this process in PD. The determination of the $\mathrm{Fe}$ oxidation state in the nerve cells representing PD and control cases may shed some new light on the role of $\mathrm{Fe}$ in the pathogenesis of PD. 
Valuable information on the speciation of metals may be provided by $\mathrm{X}$-ray absorption near-edge structure (XANES) spectroscopy. The XANES technique is a type of absorption spectroscopy. In this method we examine the modulation of the X-ray absorption probability of an atom as a function of incoming X-ray radiation energy [26]. The analyzed area of the X-ray absorption spectrum covers the energies near and above the absorption edge of the element analyzed [26, 27]. XANES is strongly sensitive to the chemistry of the absorbing atom and provides information about its oxidation state and geometry [27]. The structural and electronic data concerning the atoms analyzed can be obtained for almost any type of substances [28]. Moreover, the use of a synchrotron microbeam of X-rays allows such knowledge to be gained with the spatial resolution of single micrometers.

For a few years this measurement technique has been widely used for analysis of the oxidation state of selected elements in biological samples [29-33]. The microscopic XANES (micro-XANES) technique was applied for investigations on PD as well [34-36]. Yoshida et al. [34] investigated the chemical state of $\mathrm{Fe}$ in single neurons from SN of PD patients. The microXANES results, in this case, showed that the chemical state of $\mathrm{Fe}$ in the $\mathrm{NM}$ granules within nerve cells changed from the ferrous $\left(\mathrm{Fe}^{2+}\right)$ to the ferric $\left(\mathrm{Fe}^{3+}\right)$ form in the process of neuronal degeneration [34]. In another study, Yoshida et al. [36] investigated the differences in $\mathrm{Fe}$ oxidation state in the area of neurons, free-NM aggregates and glial cells from PD and control $\mathrm{SN}$. However, fixation of the tissue in formalin $(37 \%$ aqueous solution of formaldehyde) and also embedding in paraffin, that were applied in both cases, might have changed both the elemental composition and the oxidation state $[37,38]$.

In the present work, we the authors applied the micro-XANES technique in order to investigate differences in $\mathrm{Fe}$ chemical state for SN neurons representing PD and control groups. The measurements were done for one PD and six control samples of SN. The samples were neither fixed nor paraffinized.

\section{Experimental}

Samples

The autopsy samples of SN were examined with the use of micro-XANES spectroscopy. The absorption spectra near the Fe K-edge were measured in melanized neurons. The measurements were carried out for one sample representing PD and for six samples taken from people who had died with non-neurological conditions (control group).

The male PD patient died at the age of 77 owing to myocardial infarct. At the age of 65 he presented with a left-sided coarse $5-7-\mathrm{Hz}$ resting tremor affecting his arm and subsequently his leg. Rigidity and bradykinesia, although present, were not prominent clinical features. Five years into his disease, similar symptoms began to affect his right side. Disease progression was slow and he was started on L-dopa 6 years after the beginning of symptoms. He displayed a good response to L-dopa with the relief of bradykinesia and tremor. No cognitive decline, autonomic dysfunction, nor other atypical signs were observed. Over the past 3 years he developed wearing-off effects and dyskinesias. He remained relatively independent until his death. Additionally, brief characteristics of all the patients are given in Table 1.

All specimens were frozen and cut into $20-\mu \mathrm{m}$-thick slices with the use of a cryomicrotome (not later than $24 \mathrm{~h}$ after the time of death). The tissue slices designed for micro-XANES measurements were mounted on AP1 or ultralene foil. Both types of sample carriers are ultrapure (contain no trace elements), ultrathin (0.15 and $4 \mu \mathrm{m}$, respectively), and transparent for X-rays. Afterwards, samples prepared in such a way were freeze-dried at $-30{ }^{\circ} \mathrm{C}$ for about 1 week. After freezedrying and before measurements, the tissue sections were stored in air at room temperature. A microscopic view of one of the control SN tissue sections examined is presented in Fig. 1.

\section{Measurements}

The measurements were performed at the bending magnet beamline L at HASYLAB [39]. The Si-111 monochromator was applied. The beam was focused with the use of polycapillary optics (flux approximately $10^{9}$ photons/s). The beam was $20 \mu \mathrm{m}$ in diameter, which

Table 1 The characteristics of Parkinson's disease and control patients

\begin{tabular}{llll}
\hline Patient & Age (years) & Sex & Cause of death \\
\hline PD & 77 & Male & Myocardial infarct \\
C1 & 77 & Male & Cardiac arrest \\
C2 & 55 & Male & Cardiac arrest \\
C3 & 69 & Female & Brain hemorrhage \\
C4 & 63 & Female & Myocardial infarction with \\
& & & secondary cardiac rupture \\
C5 & 40 & Female & Septic shock \\
C6 & 65 & Male & Cardiac arrest \\
\hline
\end{tabular}




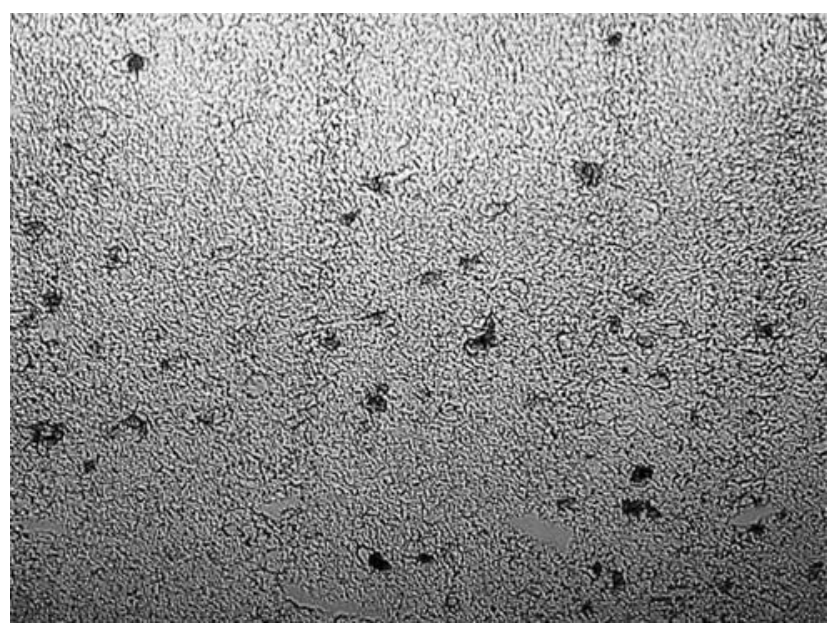

Fig. 1 Microscopic view of one of the control substantia nigra $(S N)$ tissue sections examined; nerve cells are seen as darker areas; the size of SN neuron is about $30-40 \mu \mathrm{m}$

compared with the typical size of a nerve cell from SN (30-40 $\mu \mathrm{m}$ in diameter) made possible the microXANES measurements at the single-cell level. The measurements were carried out in air. The characteristic X-ray lines of $\mathrm{Fe}$ were measured with the use of an HPGe detector (energy resolution $120 \mathrm{eV}$ for the $\mathrm{Mn} \mathrm{K} \alpha$ line, 8 - $\mu \mathrm{m}$-thick beryllium window). A schematic view of the experimental setup is presented in Fig. 2.

The absorption spectra near the Fe K-edge were measured for the energy range from 7.05 to $7.50 \mathrm{keV}$. The energy-step increments were 5, 1, 0.3, and $10 \mathrm{eV}$, respectively, for the following energy ranges: 7.05-7.08, 7.08-7.105, 7.105-7.14, and 7.14-7.50 keV. The measurement time was $10 \mathrm{~s}$ for all energy points analyzed. Besides the tissue samples, the micro-XANES spectra were measured also for reference materials (thin sections of natural minerals pyrite and andradite, bought from Micro-Analysis Consultants).

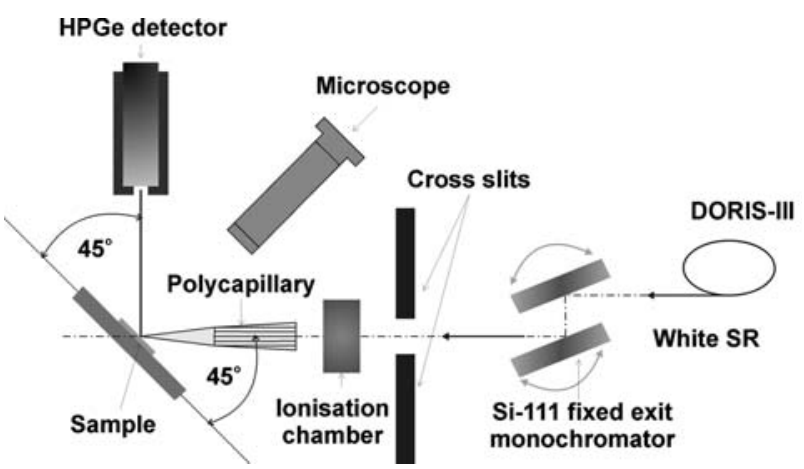

Fig. 2 The beamline L experimental setup

\section{Results and discussion}

The micro-XANES spectra of Fe were measured for SN neurons from one PD and six control samples. Typically, for each sample the analysis was carried out for one nerve cell. In order to obtain better statistics, we measured four to five spectra per nerve cell, and normalized them (point by point) to the incident photon flux and to the mean number of counts from the energy range 7.25-7.50 keV. Afterwards, we averaged the series of spectra obtained for each individual nerve cell. It is also necessary to mention that all the spectra were monitored for photoreduction, but no significant signs of the process were found.

The comparison of the micro-XANES spectra obtained for all the tissue samples analyzed and for the reference materials is presented in Figs. 3 (the entire XANES profile) and 4 (the edge region). As one can see from Fig. 3, all the micro-XANES spectra obtained for the tissue samples are situated near the spectrum measured for andradite that contains mainly $\mathrm{Fe}$ in the third oxidation state. This indicates that most of the Fe in all the nerve cell bodies examined is also oxidized and occurs as trivalent ferric $\mathrm{Fe}\left(\mathrm{Fe}^{3+}\right)$. Additionally, the energies of the pre-edge peak maximum and the first inflection point of the main edge were found and are presented in Table 2. In order to extract the preedge peak position correctly, the contribution of the edge jump to this feature was modeled using a spline function. The values shown in Table 2 are in agreement with the literature data obtained using XANES spectroscopy both for tissue and for mineral samples [40-43]. Similarly to the cited literature evidence, the pre-edge peak was located around $7,113 \mathrm{eV}$ and the first inflection point of the main edge for $\mathrm{Fe}(\mathrm{III})$ was located around 7,126 eV.

For the PD sample and one selected control sample (labeled as control 1), exceptionally, we examined the oxidation state for five and four melanized neurons, respectively, in order to investigate differences between individual neurons of the same sample. The results of the measurements were analyzed as described earlier and are shown in Fig. 5 (the edge region). No significant difference is observed between the edge positions of spectra obtained for individual neurons. The data points only scatter around a common mean edge structure. The mean from the spectra obtained for individual neurons of the PD SN sample and the control 1 sample, respectively, is shown in Figs. 6 (the entire XANES profile), 7 (the edge region), and 8 (the pre-edge peak region). At this higher level of counting statistics (edge jump $2 \times 10^{4}$ counts), the spectra of the 
Fig. 3 Comparison of the $\mathrm{Fe}$ microscopic X-ray absorption near-edge structure (micro$X A N E S$ ) spectra (the entire profiles) obtained for neurons of all the tissue samples analyzed and for the reference materials. Control 1-control 6 the control samples of $\mathrm{SN}, P D \mathrm{SN}$ sample from a patient who died with Parkinson's disease, ref $\mathrm{Fe}(I I)$ pyrite, ref $\mathrm{Fe}(I I I)$ andradite

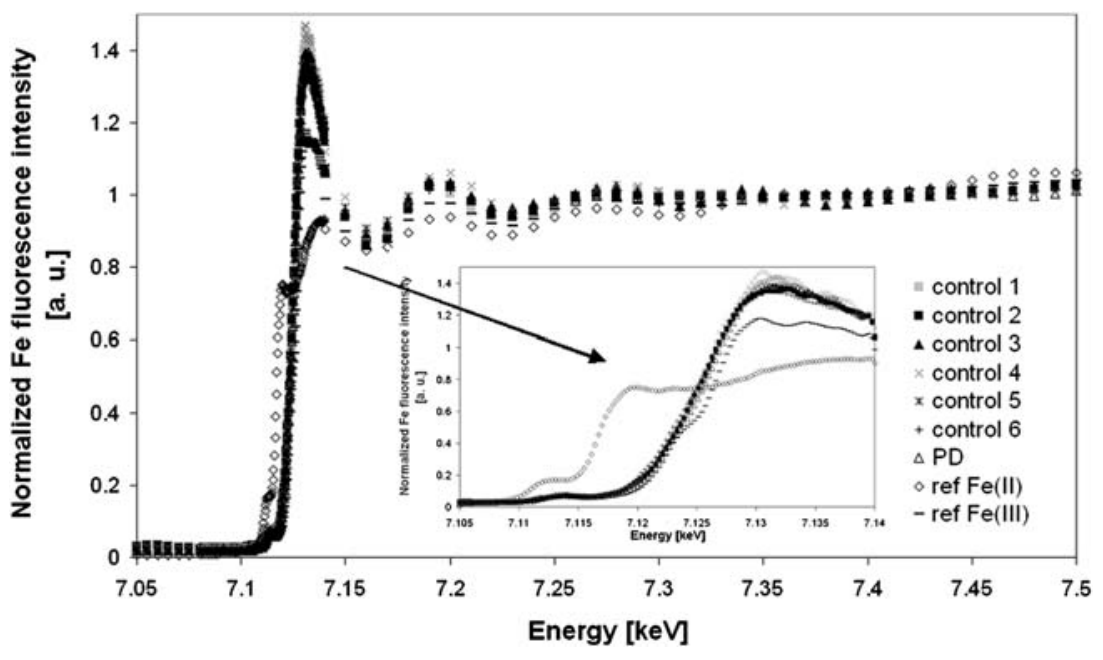

Fig. 4 Absorption spectra near the Fe K-edge (the edge region) measured in nerve cells from SN samples in comparison with the micro-XANES spectrum of andradite

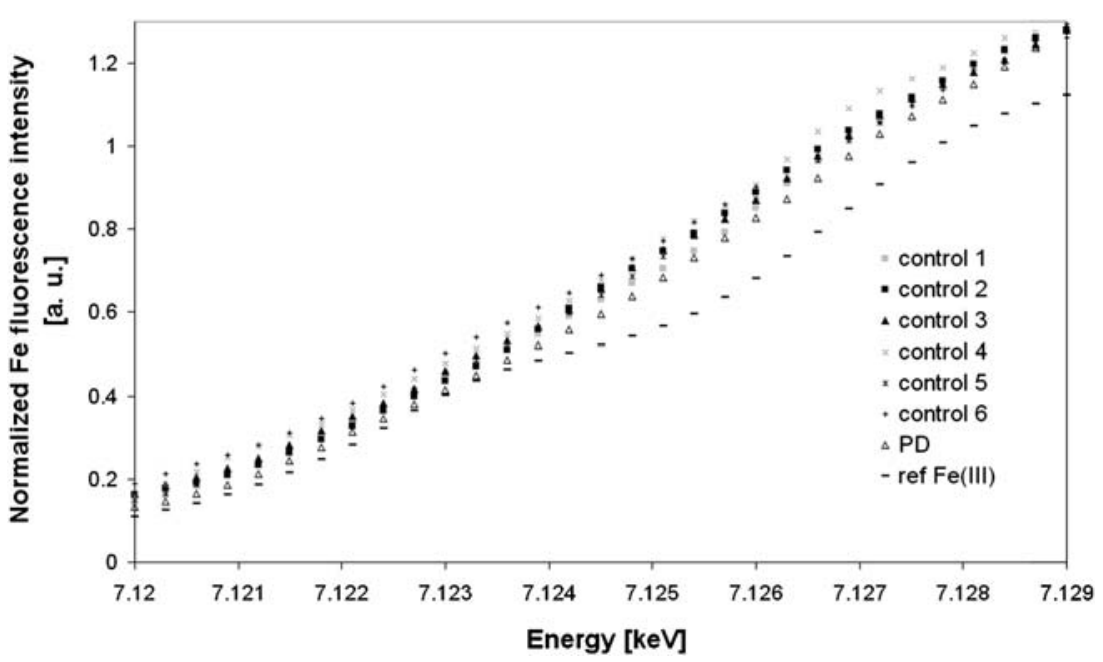

control and PD samples are indistinguishable. The differences in the edge position between the XANES spectra for individual neurons of the control and PD

Table 2 The energies of the pre-edge peak maximum and the first inflection point of the main edge for the tissue samples analyzed and for the reference samples

\begin{tabular}{lll}
\hline Sample & \multicolumn{2}{l}{ Energy $(\mathrm{eV})$} \\
\cline { 2 - 3 } & $\begin{array}{l}\text { Pre-edge peak } \\
\text { maximum }\end{array}$ & $\begin{array}{l}\text { First inflection point } \\
\text { of the main edge }\end{array}$ \\
\hline C1 & $7,113.3 \pm 0.3^{\mathrm{a}}$ & $7,126.3 \pm 0.3$ \\
C2 & $7,113.6 \pm 0.3$ & $7,125.7 \pm 0.3$ \\
C3 & $7,113.2 \pm 0.3$ & $7,126.0 \pm 0.3$ \\
C4 & $7,113.7 \pm 0.3$ & $7,125.7 \pm 0.3$ \\
C5 & $7,113.3 \pm 0.3$ & $7,126.0 \pm 0.3$ \\
C6 & $7,113.2 \pm 0.3$ & $7,126.0 \pm 0.3$ \\
PD & $7,113.5 \pm 0.3$ & $7,126.3 \pm 0.3$ \\
Ref Fe(II) & $7,112.0 \pm 0.3$ & $7,116.7 \pm 0.3$ \\
Ref Fe(III) & $7,113.4 \pm 0.3$ & $7,126.6 \pm 0.3$ \\
\hline
\end{tabular}

a The energy step applied in the appropriate region of the X-ray absorption near edge structure spectrum samples were rather the result of insufficient statistics than of changes in the oxidation state of Fe.

In summary, the results presented did not show significant differences in Fe chemical state between SN neurons of PD samples and the control samples. Moreover, we found that most of the Fe in the neurons of $\mathrm{SN}$ is present in the ferric form.

Our results seem to be in agreement with those obtained by Galazka-Friedman et al. [44] with the use of Mössbauer spectroscopy. However, because about $200-500 \mathrm{mg}$ of tissue was used in the measurements, their results should be rather regarded as averaged and to have included all the tissue (indiscriminately neurons, glial cells, endothelia, etc.). In contrast to the work of Galazka-Friedman et al. [44], we investigated the chemical state of Fe in single neurons from SN.

According to the results of Yoshida et al. [36], the X-ray absorption spectra both for control and PD SN neurons are situated closer to the XANES spectrum of $\mathrm{Fe}(\mathrm{II})$. This may result from the differences in the 
Fig. 5 Fe micro-XANES spectra (the edge region) obtained for nerve cell bodies from the PD sample and the control 1 sample
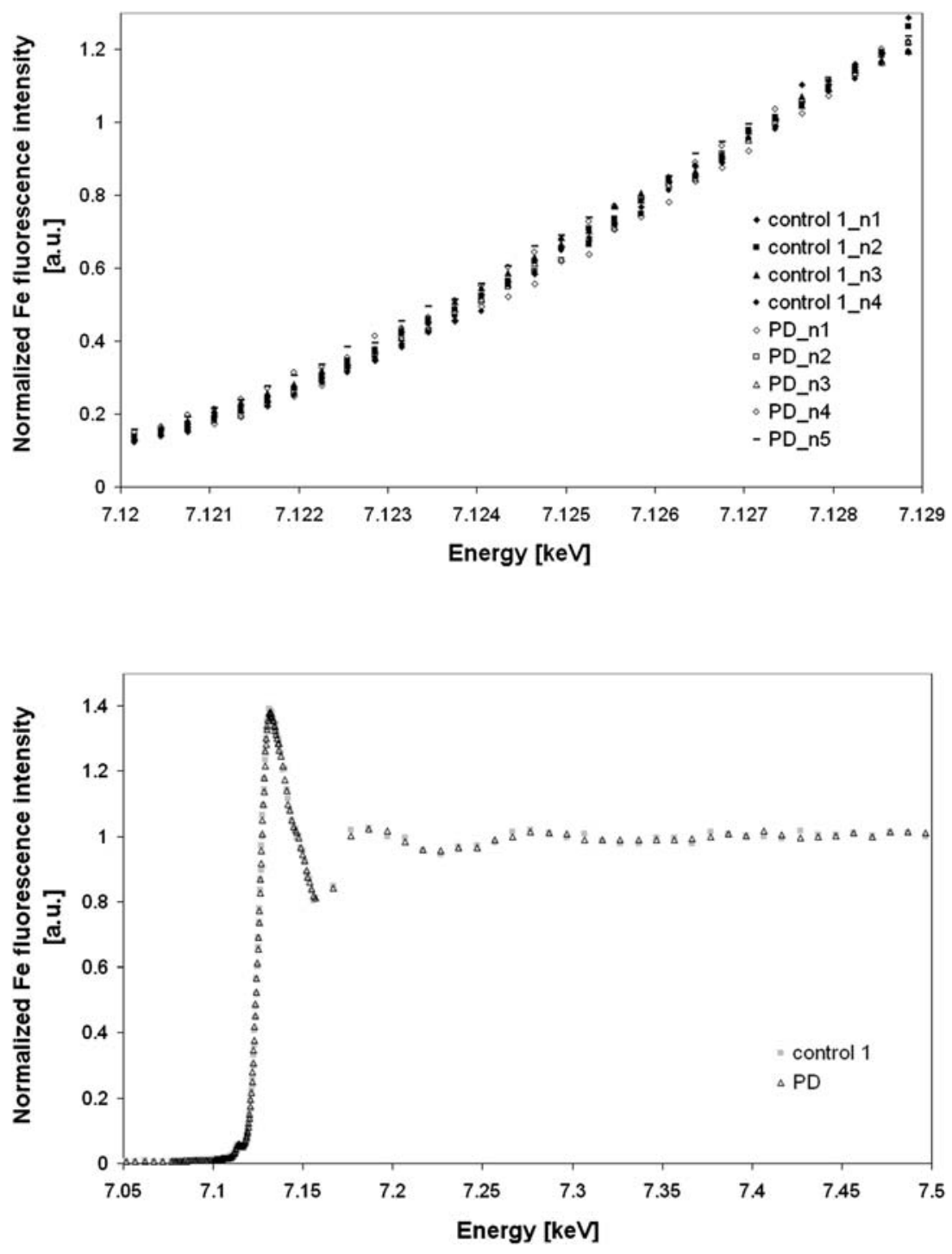

Fig. 6 Comparison of mean XANES spectra (the entire profiles) obtained for the selected control sample and the PD SN sample

Fig. 7 Comparison of mean XANES spectra (the edge region) obtained for the selected control sample and the PD SN sample

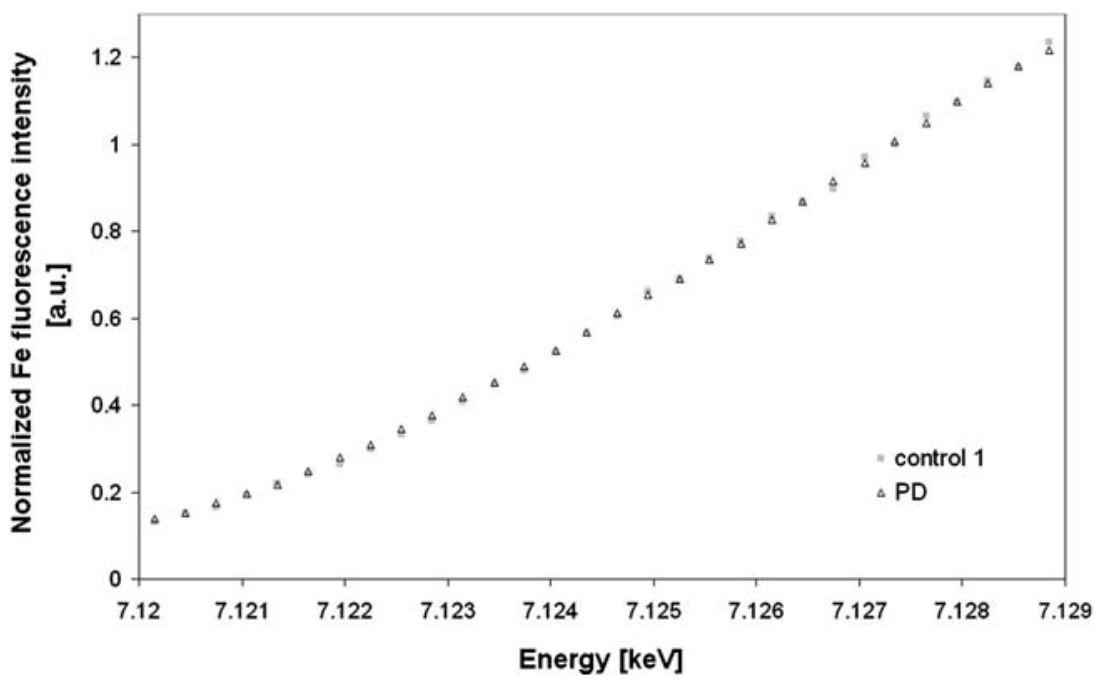


Fig. 8 Comparison of mean XANES spectra (the pre-edge peak region) obtained for the selected control sample and the PD SN sample

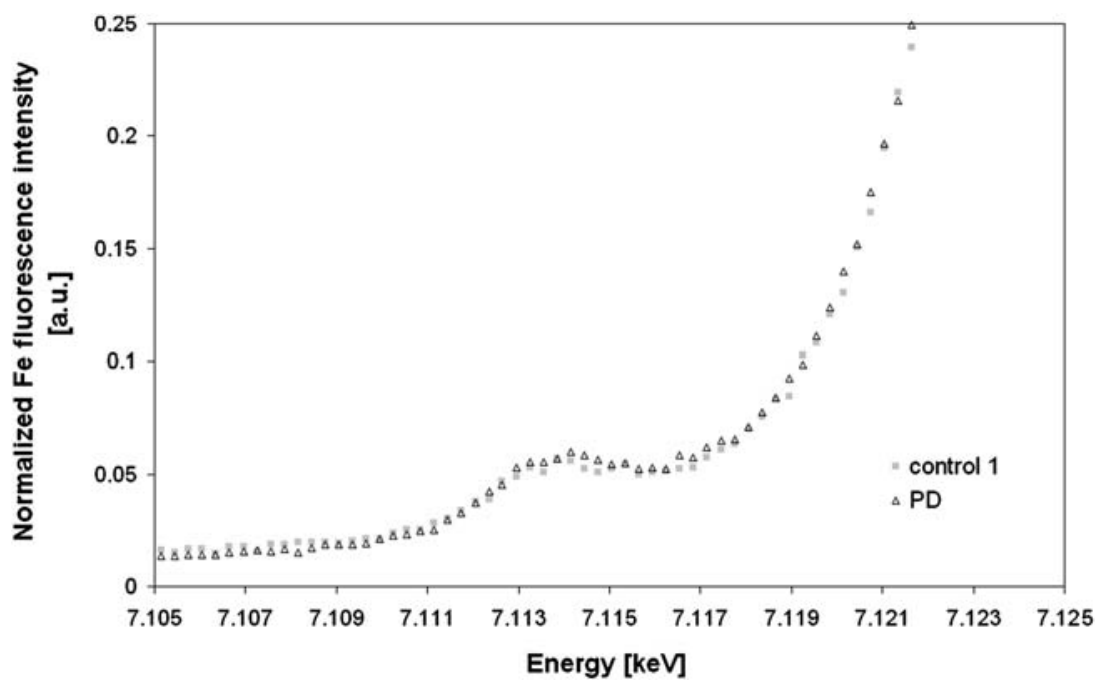

sample preparation techniques. The specimens used in their measurements were fixed in formalin. Since it is known that aldehydes oxidize easily, i.e., they act as strong reducing agents, this preparation techniques could have an effect on the Fe chemical state [38]. Moreover, the process of fixation and the duration of fixation may have marked effects on the metal ion concentrations because many metal complexes are water-soluble [45]. In this context, it is also necessary to mention that the comparison of Mössbauer spectra measured for fresh and fixed SN samples showed significant differences [45].

Moreover, in contrast to the results of Yoshida et al., we did not observe any significant differences in the pre-edge peak intensity between the Fe XANES spectra measured for control and PD neurons.

Our results seem to be in contradiction with those obtained by Sofic et al. [14]. On the basis of histochemical and biochemical results, they observed a shift of the $\mathrm{Fe}$ (II) to $\mathrm{Fe}(\mathrm{III})$ ratio in $\mathrm{SN}$ from almost 2:1 in normal brain to $1: 2$ in parkinsonian brain [14].

Further detailed studies using XANES spectroscopy are needed to confirm the effect of fixation on the oxidation state. Also, it is necessary to investigate the problem of sample oxidation both before and during measurements. Such experiments are in progress.

\section{Conclusions}

The micro-XANES measurements carried out for PD and control SN did not show any significant changes in Fe chemical state between PD and control melanized neurons. Moreover, they allowed us to state that most of the $\mathrm{Fe}$ occurred in these biological structures as $\mathrm{Fe}(\mathrm{III})$.

Acknowledgements This work was supported by the Ministry of Education and Science (Warsaw, Poland) and the following grants: Ministry of Education and Science grants 112/E-356/ SPB/DESY/P-05/DWM728/2003-2005 and 3T11E01029; IHPContract HPRI-CT-1999-00040/2001-00140 of the European Commission; the European Community Research Infrastructure Action under FP6 "Structuring the European Research Area" (through the Integrated Infrastructure Initiative "Integrating Activity on Synchrotron and Free Electron Laser Science"); and HASYLAB experimental grant II-02-092.

\section{References}

1. Samii A, Nutt JG, Ransom BR (2004) Lancet 363:1783-1793

2. Kaur D, Andersen J (2004) Ageing Res Rev 3:327-343

3. Bharath S, Hsu M, Kaur D, Rajagopalan S, Andersen JK (2002) Biochem Pharmacol 64:1037-1048

4. Adams JD, Chang ML, Klaidman L (2001) Curr Med Chem 8:809-814

5. Foley P, Riederer PJ (2000) Neurol 247(Suppl 2):82-94

6. Andersen JK (2004) J Alzheimer Dis 6:47-52

7. Gotz ME, Double K, Gerlach M, Youdim MB, Riederer P (2004) Ann N Y Acad Sci 1012:193-208

8. Wolozin B, Golts N (2002) Neuroscientist 8:22-32

9. Galazka-Friedman J, Bauminger ER, Friedman A (2002) Hyperfine Interact 2:67-271

10. Antonini A, Leenders KL, Meier D, Oertel WH, Boesiger P, Anliker M (1993) Neurology 43:697-700

11. Zecca L, Berg D, Arzberger T, Ruprecht P, Rausch WD, Musicco M, Tampellini D, Riederer P, Gerlach M, Becker G (2005) Mov Disord 20:1278-1285

12. Berg D, Hochstrasser H, Schweitzer KJ, Riess O (2006) Neurotox Res 9:1-13

13. Griffiths PD, Dobson BR, Jones GR, Clarke DT (1999) Brain 122:667-673

14. Sofic E, Riederer P, Heinsen H, Beckmann H, Reynolds GP, Hebenstreit G, Youdim MB (1988) J Neural Transm 74:199-205 
15. Sofic E, Paulus W, Jellinger K, Riederer P, Youdim MB (1991) J Neurochem 56:978-982

16. Morawski M, Meinecke C, Reinert T, Dorffel AC, Riederer P, Arendt T, Butz T (2005) Nucl Instrum Methods Phys Res Sect B 231:224-228

17. Friedman A, Bauminger ER, Galazka-Friedman J, Barcikowska M, Suwalski J, Hechel D, Dymecki J, Nowik I (1994) Neurol Neurochir Pol 28:145-155

18. Galazka-Friedman J, Bauminger ER, Friedman A, Barcikowska M, Hechel D, Nowik I (1997) Mov Disord 12: 258-260

19. Costello DJ, Walsh SL, Harrington HJ, Walsh CH (2004) J Neurol Neurosurg Psychiatry 75:631-633

20. Nielsen JE, Jensen LN, Krabbe KJ (1995) Neurol Neurosurg Psychiatry 59:318-321

21. Dekker MC, Giesbergen PC, Njajou OT, van Swieten JC, Hofman A, Breteler MM, van Duijn CM (2003) Neurosci Lett 348:117-119

22. Zucca FA, Giaveri G, Gallorini M, Albertini A, Toscani M, Pezzoli G, Lucius R, Wilms H, Sulzer D, Ito S, Wakamatsu K, Zecca L (2004) Pigment Cell Res 17:610-617

23. Gerlach M, Double KL, Ben-Shachar D, Zecca L, Youdim MB, Riederer P (2003) Neurotox Res 5:35-44

24. Faucheux BA, Martin ME, Beaumont C, Hauw JJ, Agid Y, Hirsch EC (2003) J Neurochem 86:1142-1148

25. Zecca L, Zucca F, Wilms H, Sulzer D (2003) Trends Neurosci 26:578-580

26. Newville M (2003) Fundamentals of XAFS. http://www.xafs.org/Tutorials/\#references

27. Bare SR (2005) EXAFS data collection and analysis course. http://www.cars9.uchicago.edu/xafs/APS_2005/Bare_XANES.pdf

28. Koningsberger DC, Prins R (eds) (1988) X-ray absorption: principles, applications, techniques of EXAFS, SEXAFS, and XANES. Wiley, New York

29. Parsons JG, Aldrich MV, Gardea-Torresdey JL (2002) Appl Spectrosc Rev 37:187-222
30. Ascone I, Cognigni A, Giorgetti M, Berrettoni M, Zamponi S, Marassi RJ (1999) Synchrotron Radiat 6:384-386

31. Sarkar BJ (2000) Inorg Biochem 79:187-191

32. Gunter KK, Miller LM, Aschner M, Eliseev R, Depuis D, Gavin CE, Gunter TE (2002) Neurotoxicology 23:127146

33. Nicolis I, Curis E, Deschamps P, Benazeth SJ (2003) Synchrotron Radiat 10:96-102

34. Yoshida S, Ektessabi A, Fujisawa S (2001) J Synchrotron Radiat 8:998-1000

35. Ide-Ektessabi A, Kawakami T, Watt F (2004) Nucl Instrum Methods Phys Res Sect B 213:590-594

36. Yoshida S, Ide-Ektessabi A, Fujisawa S (2003) Struct Chem 14:85-95

37. Chwiej J, Szczerbowska-Boruchowska M, Lankosz M, Wojcik S, Falkenberg G, Stegowski Z, Setkowicz Z (2005) Spectrochim Acta Part B 60:1531-1537

38. Bobrański B (1966) Chemia organiczna. 3rd edn. PWN, Warsaw

39. Falkenberg G, Clauss O, Tschentscher T (2001) Hasylab annual report. http://www-hasylab.desy.de/science/annual_reports/2001_report/index.html

40. Ortega R, Deves G, Bohic S, Simionovici A, Menez B, Bonnin-Mosbah M (2001) Nucl Instrum Methods Phys Res Part B 181:480-484

41. Ektessabi A, Shikine S, Kitamura N, Rokkum M, Johansson C (2001) X-Ray Spectrom 30:44-48

42. Sugimoto T, Ide-Ektessabi A, Ishihara R; Tanigaki M (2004) J Electron Spectrosc Relat Phenom 137-140:831-838

43. Wilke M, Farges F, Petit PE, Brown GE (2001) Am Mineral 86:714-730

44. Galazka-Friedman J, Bauminger ER, Friedman A, Barcikowska M, Hechel D, Nowik I (1997) Mov Disord 12:258-260

45. Gerlach M, Ben-Shachar D, Riederer P, Youdim $\mathrm{MBH}$ (1994) J Neurochem 63:793-807 